\title{
TAXONS OF CHICKEN CECUM MICROBIOM ARE ABUNDANT, AND INFLUENCED BY THE COMBINED FEED COMPOSITION AND DECREASED METABOLIZABLE ENERGY
}

\author{
L.A. IL'INA ${ }^{1}$, E.A. YILDIRIM ${ }^{1}$, I.N. NIKONOV ${ }^{1}$, V.A. FILIPPOVA ${ }^{1}$, G.Yu. LAPTEV ${ }^{1}$, \\ N.I. NOVIKOVA ${ }^{1}$, A.A. GROZINA ${ }^{2}$, T.N. LENKOVA ${ }^{2}$, \\ V.A. MANUKYAN ${ }^{2}$, V.I. FISININ ${ }^{2}$, I.A. EGOROV ${ }^{2}$
}

\begin{abstract}
${ }^{1}$ Biotrof+ Ltd, 7-N, 8, lit. A, Malinovskaya ul., St. Petersburg, 196602 Russia, e-mail ilina@biotrof.ru;
${ }^{2}$ All-Russian Research and Technological Poultry Institute, Federal Agency of Scientific Organizations, 10, ul. Ptitsegradskaya, Sergiev Posad-11, Moscow Province, 141300 Russia, e-mail fisinin@vnitip.ru

Acknowledgements:

Supported by Russian Science Foundation, the project «Modern understanding of gut microflora in poultry depending on feed composition: molecular and genetic approach» № 14-16-00140

Received July 24, 2015
\end{abstract}

\begin{abstract}
Currently the processed sunflower products as the cheapest source of vegetable protein are considered an alternative to soybean cake and meal in the poultry diet. However, in sunflower meal the energy value is lower, lysine rate is less than required, and the level of non-starch polysaccharides not digestible in poultry gut because of absence of specific enzymes (i.e., amylases, cellulases, etc.) are rather high. Digestion of these components is possible due to microbial enzymes. Gut content is detained in the poultry caecum for the longest time, wherein the basic processes of microbial proteolysis, and cellulose and starch destruction are performed. Using modern molecular methods of NGS-sequence analysis and real-time PCR, we investigated the number of bacteria and the structure of bacterial community in cecum of 36-day-old Cobb 500 broiler chickens fed with diets containing soybean meal or sunflower meal. Contrary to traditional view, the composition of caecum microbiom was very abundant and divers, and included the obligate gut microflora (Clostridiaceae, Eubacteriaceae, Lactobacillaceae, Bacteroidetes) and non-identified taxons. Moreover, the typical gut microorganisms (i.e., enterococcus, bifidobacterium) were minor and the pathogenic bacteria of genera Camphylobacter sp., Staphylococcus sp. were not detected. Our results first characterized in detail the caecum microbiome as influenced by the combined factors such as specific composition and decreased metabolizable energy in feed. This study showed that the feed containing $25 \%$ sunflower meal caused a 14.7-fold increase in total number of bacteria while the number of phylum Bacteroides amylolytics was 1.4-times lower, the family Clostridiaceae was 1.2-times less abundant and the cellulosolytics families Ruminococcaceae and Lachnospiraceae were 1.16-times and 1.48-times depressed, respectively, thus indicating limitations in the metabolism of hydrolysable components and cellulose in the poultry gut. Moreover, the obligate bacterial intestinal flora changed in number. Particularly, there were a 3.04-fold increase in genera Lactobacillus sp., a 1.5-fold increase in order $\mathrm{Ba}$ cillales, 3-fold decrease in genera Bifidobacterium sp. and 10-fold decrease in genera Enterococcus sp. Also the bacterial number in genera Escherichia sp. was found to be 55-fold lower, and families Sutterellaceae and Erysipelotrichaceae, including species that might cause disbiotic diseases, were depressed 2.5 times and 1.8 times, respectively. Moreover, our research showed that the changes in the cecum bacterial community due to the sunflower meal containing feed depressed the chickens' performance. Thus, the weight of 36-day-old chickens (males and females) was the highest in the control group not fed with sunflower meal $(2142.0 \pm 45.40 \mathrm{~g})$ compared to the experimental poultry $(2017.0 \pm 53.30 \mathrm{~g})$ in which the feed consumption increased by $13 \%$.
\end{abstract}

Keywords: microflora of cecum, chicken, performance in broilers, bacterial community, NGS-sequencing, real-time PCR.

Sunflower processing products in poultry diets as the cheapest source of vegetable protein attracts arttention of many experts. However, the disadvantages of such feed should be considered. In particular, compared to soy meal, sunflower meal not only has a lower energy value (139-209 kcal per $100 \mathrm{~g}$ ) and contains $1.5 \%$ less lysine than required for poultry, but also contains a substantially greater amount of non-starch polysaccharides, mainly cellulose, hemicellulose, 
pectins and lignin [1, 2]. Note, poultry is not capable of independent digestion of non-starch polysaccharides due to lack of the necessary enzymes (amylases, cellulases, etc.). Digestion of these components is only possible due to microbial enzymes, and therefore it is difficult to overestimate the role of microorganisms in poultry digestion. Along with nutrient cleavage to available products, they further provide poultry with many essential nutrients, e.g. proteins, hormones, vitamins, compounds possessing antibiotic properties, etc. [3-6].

Microbiology of digestion is very complex and poorly understood [7-9[ which, in particular, explains the relevance of the research of poultry intestine under different diets. Most of the available information about this microflora was obtained using classical microbiological methods, according to which the basis a community is made up with bifidobacteria, streptococci, lactobacilli, lactate fermenting bacteria, eubacteria, bacteroides and enterobacteria $[3,10,11]$, but, obviously, a substantial part of the gastrointestinal tract (GIT) microorganisms are the uncultured species [12].

Contemporary molecular genetic techniques open unique opportunities to study the microbiota composition. Up to 140 bacterial genera were found in poultry intestine, of which $10 \%$ only have been identified by bacterial $16 \mathrm{~S}$ rRNA gene, and the other ones belong to new species and, possibly, genera [1315]. Resolution and performance of PCR analysis and NGS sequencing (next generation sequencing) provide reliable information about all the changes in the intestinal microbiome due to the effects of certain factors [16]. Despite the widespread use of these methods to study of numbers and taxonomic diversity of microbes in the human intestine [17, 18], there are only a few reports on poultry. In particular, they relate to the GIT microbiome state in poultry infected by pathogenic bacteria Campylobacter jejuni $[19,20]$ due to the effects of coccidiostats [21] and in relation to the productivity [22, 23].

In this study, using NGS-sequence analysis and real-time PCR, we demonstrated that, contrary to the traditional understanding, cecum microbiome in broilers has an abundant and diverse taxonomic structure and includes both obligate gut microflora and unidentified taxa, while enterococci and bifidobacteria occupy a minor position in the community, and the typical pathogens are completely absent. For the first time, a detailed characterization was given to the changes in the structure of cecum microbiome in broilers as influenced by sunflower meal, which resulted in a production decrease.

The purpose of this study was to investigate the features of the cecum bacterial community in broiler chickens fed with diets containing soybean meal or sunflower meal.

Technique. Experiments were conducted in the «Zagorsk Experimental Farm of VNITIP» vivarium in 4 groups of Cobb 500 chickens (35 similar in live weight specimens per group). Chickens were fed with the combined feed of the nutritional value recommended by the Research and Technological Poultry Institute (VNITIP) [1]. A compound feed (VNITIP) without sunflower meal (control) and with $25 \%$ sunflower meal (EFKO, Russia) was introduced in the diets of 21-day old chickens, with a $4.88 \mathrm{kcal} / 100 \mathrm{~g}$ decrease in the metabolizable energy and a $1.01 \%$ decrease in the raw protein. Weight of chickens was estimated at days 21 and 36 by individual weighing, and feed consumption was recorded by daily registration of the given feed and the residue according to conventional techniques [24]. Collection of cecum content for molecular genetic studies was performed in 6 chickens ( 3 specimens from each group) at slaughter in the age of 36 days in strict compliance with sterility [25].

Total DNA was isolated from the samples using Genomic DNA Purification Kit (Fermentas Inc., Lithuania) according to manufacturer's recommen- 
dations. Composition and structure of bacterial populations were estimated by NGS sequencing. Amplification was performed using a Verity device (Life Technologies Inc., USA) and 343F/806R primers (5'-CTCCTACGGRRSGCAGCAG-3' and 5'-GGACTACNVGGGTWTCTAAT-3'), flanking a 16S rRNA V3V4 gene region. Sequencing was performed using a MiSeq system (Illumina Inc., USA) with MiSeq Reagent Kit v3 (Illumina Inc., USA) according to manufacturer's recommendations. To process $2 \times 300$ bp reads and estimate taxonomic affiliation of DNA sequences up to the genus, a CLC Bio GW 7.0 bioinformatics platform (Qiagen N.V., Netherlands) was used. Real-time PCR to account for the total number of bacteria was performed using a DT Lite-4 amplifier (LLC NPO DNA Technology, Russia) with the Reagents for RT-PCR in the presence of intercalating EVA Green stain Kit (Syntol, Russia) and Eub338/Eub518 (5'ACTCCTACGGGAGGCAGCAG-3' and 5'-ATTACCGCGG-CTGCTGG-3') primers, in the following regime: $3 \mathrm{~min}$ at $95{ }^{\circ} \mathrm{C}$; 40 cycles including $13 \mathrm{sec}$ at $95{ }^{\circ} \mathrm{C}, 13 \mathrm{sec}$ at $57.6{ }^{\circ} \mathrm{C}, 30 \mathrm{sec}$ at $72{ }^{\circ} \mathrm{C}$.

Mathematical and statistical processing was performed using Microsoft Excel 2010.

Results. In this study, we focused on the cecum microbiome, as it is known that the intestine content remains here for the longest time, and the basic processes of microbial proteolysis and cellulose and starch cleavage take place in cecum $[26,27]$. The results confirmed the unequal impact of the test diets on the microbiome structure.

With the taxonomic analysis of DNA sequences, their significant proportion $(7.17 \pm 0.28 \%$ in control, $7.91 \pm 0.37 \%$ in the experiment) could not be attributed to any known taxon (Table 1). This has been reported previously [12-15], which indicates a complete lack of the knowledge about the existence of these taxa, and therefore of the attempts to study them. Based on the results of the analysis, the identified bacteria were assigned to five phyla. In cecum, the representatives of phylum Firmicutes and families Ruminococcaceae $(19,81 \pm 0,97 \%)$ and Clostridiaceae $(23,06 \pm 1,19 \%)$ having amyloid and cellulolytic enzymes and of phylum Bacteroidetes $(29,60 \pm 1.49 \%)$ with amylo- and proteolytic activity were predominant. Our results confirmed the data of several authors who have demonstrated by NGS sequencing predominance of phylum Firmicutes [19, 21] and genera Clostridium and Bacteroides bacteria [23] in broiler cecum. At the same time, our results are contrary to other reports which indicated the dominance of the phylum Proteobacteria representatives [22]. Probably, some variations in the analysis of poultry cecum microflora by NGS sequencing may be due to the differences in the study 16S rRNA gene region and instrument base, and to other factors such as climatic conditions, sanitary hygienic environment, diet, use of antibiotics, poultry age and cross [19, 21].

1. Number and proportion of bacterial taxa in the cecum of 36 day-old Cobb 500 broilers depending on the diet $(X \pm X$, «Zagorsk Experimental Farm of VNITIP» vivarium, 2015)

\begin{tabular}{ccc}
\hline \multicolumn{1}{c}{ Parameter } & Group I (control, $n=3)$ & Group II $(n=3)$ \\
\hline Total number of bacteria, eq. genomes/g of content & $3.4 \times 10^{9} \pm 1.6 \times 10^{8}$ & $5.0 \times 10^{10} \pm 1.4 \times 10^{9}$ \\
Taxon frequency, $\%$ & & \\
phylum Bacteroidetes & $29.60 \pm 1.49$ & $21.13 \pm 0.95^{*}$ \\
genus Bacteroides sp. & $18.50 \pm 0.93$ & $16.62 \pm 0.83^{*}$ \\
genus Alistipes sp. & $10.62 \pm 0.52$ & $4.39 \pm 0.20^{*}$ \\
unclassified Rikenellaceae & $0.39 \pm 0.02$ & $0.10 \pm 0.01^{*}$ \\
phylum Firmicutes & $58.48 \pm 2.94$ & $68.95 \pm 2.75^{*}$ \\
unclassified Firmicutes & $6.55 \pm 0.34$ & $5.84 \pm 0.04^{*}$ \\
class Clostridia & $42.12 \pm 2.01$ & $35.49 \pm 1.77^{*}$ \\
unclassified Clostridia & $0.55 \pm 0.13$ & $0.66 \pm 0.03$ \\
unclassified Clostridiales & $7.53 \pm 0.36$ & $9.35 \pm 0.34^{*}$ \\
family Clostridiaceae & $23.06 \pm 1.19$ & $19.43 \pm 0.87^{*}$
\end{tabular}




\begin{tabular}{lcc} 
& & Continued Table 1 \\
genus Clostridium sp. & $7.47 \pm 0.33$ & $5.15 \pm 0.22^{*}$ \\
genus Butyricicoccus sp. & $3.25 \pm 0.15$ & $1.36 \pm 0.06^{*}$ \\
genus Flavonifractor sp. & $0.90 \pm 0.04$ & $0.22 \pm 0.01^{*}$ \\
genus Pseudoflavonifractor sp. & $0.73 \pm 0.03$ & $0.57 \pm 0.02^{*}$ \\
genus Oscillibacter sp. & $0.60 \pm 0.03$ & $0.10 \pm 0.00^{*}$ \\
family Ruminococcaceae & $19.81 \pm 0.97$ & $17.14 \pm 0.84^{*}$ \\
unclassified Ruminococcaceae & $13.05 \pm 0.64$ & $11.13 \pm 0.50^{*}$ \\
genus Faecalibacterium sp. & $5.98 \pm 0.29$ & $5.14 \pm 0.22^{*}$ \\
genus Subdoligranulum sp. & $0.40 \pm 0.02$ & $0.36 \pm 0.02$ \\
genus Ruminococcus sp. & $0.29 \pm 0.02$ & $0.17 \pm 0.01^{*}$ \\
family Eubacteriaceae & $0.14 \pm 0.02$ & $0.16 \pm 0.01$ \\
family Lachnospiraceae & $1.12 \pm 0.05$ & $0.76 \pm 0.04^{*}$ \\
genus Lactobacillus sp. & $8.80 \pm 0.43$ & $26.79 \pm 0.65^{*}$ \\
genus Enterococcus sp. & $0.10 \pm 0.00$ & $0.01 \pm 0.00^{*}$ \\
order Bacillales & $0.29 \pm 0.01$ & $0.45 \pm 0.02^{*}$ \\
family Erysipelotrichaceae & $0.47 \pm 0.02$ & $0.19 \pm 0.01^{*}$ \\
phylum Actinobacteria & $0.60 \pm 0.03$ & $1.27 \pm 0.05^{*}$ \\
genus Bifidobacterium sp. & $0.18 \pm 0.01$ & $0.06 \pm 0.00^{*}$ \\
family Coriobacteriaceae & $0.42 \pm 0.02$ & $0.51 \pm 0.02^{*}$ \\
phylum Proteobacteria & $4.14 \pm 0.21$ & $0.74 \pm 0.03^{*}$ \\
genus Escherichia sp. & $2.77 \pm 0.12$ & $0.05 \pm 0.00^{*}$ \\
family Sutterellaceae & $0.59 \pm 0.03$ & $0.33 \pm 0.11^{*}$ \\
genus Bilophila sp. & $0.30 \pm 0.01$ & $0.06 \pm 0.01^{*}$ \\
phylum Tenericutes (genus Anaeroplasma sp.) & $0.01 \pm 0.00$ & - \\
unclassified sequences & $7.17 \pm 0.28$ & $7.91 \pm 0.37^{*}$ \\
\hline N o t e. In the groups I and II the basic diet was fed without & sunflower meal and with $25 \%$ of sunflower meal \\
(with a 4.88 kcal/100 g decrease in the metabolizable energy and a $1.01 \%$ decrease of raw protein), respectively. A \\
dash means that the number of microorganisms was below the limit of reliable quantification by NGS sequencing. \\
* Differences with the control are significant at p $\leq 0.05$. & & \\
\hline
\end{tabular}

Other bacteria with cellulose- and amylolytic properties belonging to families Lachnospiraceae $(1.12 \pm 0.05 \%)$ and Eubacteriaceae $(0.14 \pm 0.01 \%)$ were fewer (Table 1). Earlier, the Lachnospiraceae and Ruminococcaceae bacteria were thought to inhabit the rumen of ruminants only [4]. In addition, due to the high sensitivity of NGS sequencing, representatives of genera $A l-$ istipes and Faecalibacterium, the producers of short chain fatty acids, were identified; before this, researchers could not detect these bacteria using other molecular genetic methods [28]. The proportion of Escherichia sp. was also low $(2.77 \pm 0.12 \%)$ which was not consistent with the traditional view on them as typical inhabitants of poultry intestines [4].

We found a high proportion of obligate representatives of poultry GIT belonging to genus Lactobacillus $(8.80 \pm 0.43 \%)$ that are able to compete and supersede pahogens due to the synthesis of organic acids and bacteriocins [3]. It should be noted that some researchers have identified a considerable percentage of genus Lactobacillus [23] representatives in cecum.

Other bacteria of family Bifidobacteriaceae and genus Enterococcus sp. with similar properties were in minority (less than $1 \%$ ) in the community, which is also not consistent with traditional concepts. The bacteria belonging to phyla Actinobacteria, Tenericutes, families Erysipelotrichaceae, and Sutterellaceae were also in minority. Interestingly, other obligate inhabitants of poultry GIT microflora, such as lactate fermenting (Selenomonas sp., Megasphaera sp.) and typical pathogenic species (Campylobacter sp., Staphylocossus sp.) that inhabit GIT, were not found in the studied chickens' cecum.

Supplementing broiler feed with $25 \%$ of sunflower meal resulted in a 14.7-fold increase in the total number of bacteria (Table 1). Soluble non-starch polysaccharides are known to be capable of increasing chyme viscosity and forming insoluble polymer matrix which prevents the even mixing of the digestive mass, thereby reducing the intensity of wall digestion [29]. Therefore, the less intense movement of the content of poultry GIT facilitated the accumulation of bacteria and, accordingly, an increase in their total number.

In the cecum microbiome in group II broiler chickens the proportion of 
phylum Bacteroidetes sp. and family Clostridiaceae bacteria which usually have starchy polysaccharide cleavage enzymes (amylase, etc.) decreased significantly, i.e. 1.40 and 1.20 times, respectively. In addition, the percentage of cellulolytics, that is Ruminococcaceae and Lachnospiraceae families also decreased 1.16 times and 1.48 times, respectively. Thus, the increase in the content of non-starch polysaccharides in the diet resulted in a decrease in the number of bacteria with amylo- and cellulolytic properties, indicating a decrease in metabolic activity of hydrolysable components and feed fiber.

Also, a discrepancy between our results and the traditional assertion that a high content of non-starch polysaccharides in animal feed and, consequently, slower movement of the intestinal contents contribute to the growth of the number of pathogenic and other undesirable microorganisms was revealed. On the contrary, our findings suggest the opposite effect. Under supplementing diet with $25 \%$ of sunflower meal, there was a significant 1.80 -fold decrease in the proportion of infectious pathogens belonging to family Sutterellaceae, a total number of family Erysipelotrichaceae decreased 2.50 times, and the persentage of genus Escherichia sp., among which the species capable of causing disbiotic violations in macroorganisms can be found, decreased 55 times (Table 1). Moreover, the diet supplemented with sunflower meal increased the percentage of obligate representatives of poultry intestinal normal flora (i.e. lactic acid bacteria of genus Lactobacillus increased 3.04-fold and bacilli of order Bacillales increased 1.50-fold), that are usually capable of antagonistic displacement of pathogenic species due to the synthesis of organic acids and bacteriocins [3]. At the same time, a significant decrease was observed in the proportion of other bacteria with similar properties that were found in cecum in minority, in particular, the genera Bifidobacterium sp. number decreased 3 times and Enterococcus sp. decreased 10 times.

Productivity of broiler chickens studied was associated with the changes in the structure of the bacterial cenosis (Table 2). The highest productivity values were observed in the group where the diet of chickens was not supplemented with sunflower meal.

2. Dynamics of productivity in Cobb 500 broiler chickens depending on the diet ( $X \pm X$, «Zagorsk Experimental Farm of VNITIP» vivarium, 2015)

\begin{tabular}{|c|c|c|}
\hline Parameter & Group I (control, $n=35$ ) & Group II (experiment, $n=35$ ) \\
\hline Preservation, \% & 100.0 & 97.1 \\
\hline \multicolumn{3}{|l|}{ Live weight, g: } \\
\hline 1-day-old & $44.00 \pm 0.20$ & $44.00 \pm 0.17$ \\
\hline 21-day-old & $870.00 \pm 20.40$ & $875.00 \pm 19.75$ \\
\hline 36-day-old & $2142.00 \pm 45.40$ & $2017.00 \pm 53.30^{*}$ \\
\hline \multicolumn{3}{|l|}{ including } \\
\hline male chickens & $2380.00 \pm 34.42$ & $2261.00 \pm 36.12 *$ \\
\hline female chickens & $1904.00 \pm 27.92$ & $1773.00 \pm 34.17^{*}$ \\
\hline \multicolumn{3}{|l|}{ Average daily weight gain, g: } \\
\hline day 1 to day 36 & $58.30 \pm 2.30$ & $54.81 \pm 2.19^{*}$ \\
\hline during the experiment (days 22-36) & $84.80 \pm 3.12$ & $76.13 \pm 2.14 *$ \\
\hline \multicolumn{3}{|l|}{ Feed consumption, kg: } \\
\hline total & $3.44 \pm 0.15$ & $3.69 \pm 0.12$ \\
\hline during the experiment (days 22-36) & $2.25 \pm 0.10$ & $2.28 \pm 0.08$ \\
\hline \multicolumn{3}{|l|}{ Feed spending, kg: } \\
\hline days $1-36$ & $1.64 \pm 0.04$ & $1.87 \pm 0.06^{*}$ \\
\hline days $22-36$ & $1.77 \pm 0.07$ & $2.00 \pm 0.10^{*}$ \\
\hline $\begin{array}{l}\text { Note. Groups I and II: basic diet } \\
\mathrm{g} \text { decrease in the amount of metabo } \\
{ }^{*} \text { Differences with the control are sig }\end{array}$ & $\begin{array}{l}\text { nflower meal and with } 25 \% \text { of } \\
\text { gy and a } 1.01 \% \text { of raw protein } \\
\leq 0.05 \text {. }\end{array}$ & $\begin{array}{l}\text { unflower meal with a } 4.88 \mathrm{kcal} / 100 \\
\text { lecrease. }\end{array}$ \\
\hline
\end{tabular}

Thus, by the NGS sequencing and PCR analysis, we first demonstrated that, contrary to traditional ideas, cecum microbiocenosis in broiler chickens was characterized by abundant and diverse taxonomic structure and included both obligate poultry gastrointestinal tract (GIT) representatives (families Clos- 
tridiaceae, Eubacteriaceae, Lactobacillaceae, phylum Bacteroidetes), and a number of unidentified taxa. A generally accepted understanding was also contradicted with our findings on the minority position of enterococci and bifidobacteria in the community and on the absolute lack of typical pathogenic poultry GIT microorganisms (Camphylobacter sp., Staphylocossus sp.). Supplementing chicken diet with $25 \%$ of sunflower meal resulted in a change in the number and structure of cecum microbiome and was associated with a significant reduction of poultry productive qualities. The use of molecular techniques (NGS sequencing and real-time PCR) makes it possible to perform a detailed analysis of the microbial population structure, its dependence on feeding and to study the microbiology of digestion considering it as a factor of stability, viability and productivity in poultry.

\section{REFEREN C ES}

1. Fisinin V.I., Egorov I.A., Okole lova T.M., I mangulov Sh.A. Kormlenie sel'skokhozyaistvennoi ptitsy [Feeding in poultry]. Sergiev Posad, 2001.

2. Normy i ratsiony kormleniya sel'skokhozyaistvennykh zhivotnykh. Spravochnoe posobie /Pod redaktsiei A.P. Kalashnikova, V.I. Fisinina, V.V. Shcheglova, N.I. Kleimenova [Feed norms and rations for arm animals: handbook. A.P. Kalashnikov, V.I. Fisinin, V.V. Shcheglov, N.I. Kleimenov (eds.)]. Moscow, 2003.

3. Ti mos h k o M.A. Mikroflora pishchevaritel'nogo trakta sel'skokhozyaistvennykh zhivotnykh [Microflora of gastrointestinal tract in farm animals]. Kishinev, 1990.

4. Tarakanov B.V. Metody issledovaniya mikroflory pishchevaritel'nogo trakta sel'skokhozyaistvennykh zhivotnykh i ptitsy [Study of gastrointestinal microflora in farm animals and poultry]. Moscow, 2006.

5. Salanitro J., Fairchilds I., Zgornicki Y. Isolation, culture characteristics, and identification of anaerobic bacteria from the chicken cecum. Appl. Microbiol., 1974, 27: 678-687.

6. St a nley D., H ughes R.J., M o ore R.J. Microbiota of the chicken gastrointestinal tract: influence on health, productivity and disease. Appl. Microbiol. Biotechnol., 2014, 98: 43014309 (doi: 10.1007/s00253-014-5646-2).

7. Zdunczyk Z., Jankowski J., Kaczmarek S. Determinants and effects of postileal fermentation in broilers and turkeys part 1: gut microbiota composition and its modulation by feed additives. World's Poult. Sci. J., 2015, 71(1): 37-57 (doi: 10.1017/S0043933915000045).

8. Stanley D., D en man S.E., Hughes R.J., Ge i e r M.S., Crowley T.M., Che n H. Intestinal microbiota associated with differential feed conversion efficiency in chickens. Appl. Microbiol. Biotechnol., 2012, 96: 1361-1369 (doi: 10.1007/s00253-011-3847-5).

9. Torok V.A., $\mathrm{H} \mathrm{ughes}$ R.J., $\mathrm{M}$ ik k e $\mathrm{s} \mathrm{se} \mathrm{n}$ L.L. Identification and characterization of potential performance-related gut microbiota in broiler chickens across various feeding trials. Appl. Environ. Microbiol., 2011, 77(17): 5868-5878 (doi: 10.1128/AEM.00165-11).

10. B a r n e s E. The intestinal microflora of poultry and game birds during life and after storage. $J$. App. Bacteriol., 1979, 46: 407-419 (doi: 10.1111/j.1365-2672.1979.tb00838.x).

11. M e a d G.C. Microbes of the avian cecum: types present and substrates utilized. J. Exp. Zool., 1989, 3: 48-54 (doi: 10.1002/jez.1402520508).

12. Engberg R., Hed e mann M., Le s s e r T., J e n se n B. Effect of zinc bacitracin and salinomicin on intestinal microflora and performance of broilers. Poultry Sci., 2000, 79: 13111319 (doi: 10.1093/ps/79.9.1311).

13. Apajalahti J., Kettune $\mathrm{n}$ A., Graham H. Characteristics of the gastrointestinal microbial communities, with special reference to the chicken. World Poult. Sci. J., 2004, 60: 223232 (doi: 10.1079/WPS200415).

14. Gong J., Forster R.J., Yu H., Chambers J.R., Sabour P.M., Whe at croft R., $\mathrm{Ch}$ en S. Diversity and phylogenetic analysis of bacteria in the mucosa of chicken ceca and comparison with bacteria in the cecal lumen. FEMS Microbiol. Lett., 2002, 208: 1-7 (doi: 10.1016/S0378-1097(01)00521-3).

15. A m it - Ro ma ch E., S k lan D., U n i Z. Microflora ecology of the chicken intestine using 16S ribosomal DNA primers. Poult. Sci., 2004, 83: 1093-1098 (doi: 10.1093/ps/83.7.1093).

16. Diaz-S a n chez S., Hanning I., Pend let on S., D' S ouza D. Next-generation sequencing: the future of molecular genetics in poultry production and food safety. Poult. Sci., 2013, 92: 562-572 (doi: 10.3382/ps.2012-02741).

17. Arumugam M., Ra es J., Pelletier E., Le Paslier D., Yamada T., Mende D.R. Enterotypes of the human gut microbiome. Nature, 2011, 473: 174-180 (doi: 10.1038/nature09944).

18. Yatsunenko T., Rey F.E., Manary M.J., Trehan I., Dominguez-Be 1- 
lo M.G., Contre ras M. Human gut microbiome viewed across age and geography. Nature, 2012, 486: 222-227 (doi: 10.1038/nature11053).

19. Qu A., B rulc J., Wils on M., Law B., The oret J., Joe ns L. Comparative metagenomics reveals host specific metavirulomes and horizontal gene transfer elements in the chicken cecum microbiome. PLOS ONE, 2008, 3: e2945 (doi: 10.1371/journal.pone.0002945).

20. Mohd Shaufi M.A., S i e o C.C., Chong C.W., Gan H.M., Ho Y.W. Deciphering chicken gut microbial dynamics based on high-throughput 16S rRNA metagenomics analyses. Gut Pathogens, 2015, 7: 4-16 (doi: 10.1186/s13099-015-0051-7).

21. D a n z e i s e n J.L., K i m H.B., I s a a c s o n R.E., T u Z.J., J o h n s o n T.J. Modulations of the chicken cecal microbiome and metagenome in response to anticoccidial and growth promoter treatment. PLoS ONE, 2011, 6: e27949 (doi: 10.1371/journal.pone.0027949).

22. Singh K., Shah T., D e shpande S., Jakhes ara S., Koringa P., Rank D. High through put $16 \mathrm{~S}$ rRNA gene-based pyrosequencing analysis of the fecal microbiota of high FCR and low FCR broiler growers. Mol. Biol. Rep., 2012, 39: 10595-10602 (doi: 10.1007/s11033012-1947-7).

23. Stanley D., Den man S.E., Hughes R.J., Ge i e r M.S., C row ley T.M., Che n H. Intestinal microbiota associated with differential feed conversion efficiency in chickens. Appl. Microbiol. Biotechnol., 2012, 96: 1361-1369 (doi: 10.1007/s00253-011-3847-5).

24. Metodika provedeniya nauchnykh i proizvodstvennykh issledovanii po kormleniyu sel'skokhozyaistvennoi ptitsy. Molekulyarno-geneticheskie metody opredeleniya mikroflory kishechnika /Pod redaktsiei V.I. Fisinina [Scientific and practical study of feeding in poultry. Molecular genetic assay of gut microflora. V.I. Fisinin (ed.)]. Sergiev Posad, 2013.

25. Instruktsiya po sanitarno-mikrobiologicheskomu kontrolyu tushek, myasa ptitsy, ptitseproduktov, yaits i yaitseproduktov na ptitsevodcheskikh i pererabatyvayushchikh predpriyatiyakh [Instruction for sanitary and microbiological control of carcasses, meat, products, eggs and egg products at poultry farms and processing enterprises]. Moscow, 1990.

26. Stanley D., Hughes R.J., M o ore R.J. Microbiota of the chicken gastrointestinal tract: influence on health, productivity and disease. Appl. Microbiol. Biotechnol., 2014, 98: 4301-4310 (doi: 10.1007/s00253-014-5646-2).

27. Rehman H., Vahjen W., Aw ad W., Z e n te k J. Indigenous bacteria and bacterial metabolic products in the gastrointestinal tract of broiler chickens. Arch. Anim. Nutr., 2007, 61: 319-335 (doi: 10.1080/17450390701556817).

28. Torok V., A 11 is on G., Percy N., O p he l-Kelle r K., Hughes R. Influence of antimicrobial feed additives on broiler commensal posthatch gut microbiota development and performance. Appl. Environ. Microbiol., 2011, 77: 3380-3390 (doi: 10.1128/AEM.02300-10).

29. R e dig P. The avian ceca: obligate combustion chambers or facultative afterburners? - The conditioning influence of diet. J. Exp. Zool., 1989, 3: 66-69 (doi: 10.1002/jez.1402520511). 